\title{
Como ler a obra de Gayle Rubin?
}

\section{Deviations: A Gayle Rubin Reader.}

RUBIN, Gayle.

London: Duke University Press, 2011. Edição para Kindle.'

"When we go to the library to find out about something, we encounter a huge heap of literature all at once. This creates a tendency to treat a large body of texts as if they all exist on the same temporal plane. But the various layers of accretion were produced at specific moments and under specific conditions. It is important to understand texts in their times. This allows us to think about the temporal aspects of their relationships to one another, and to distinguish the dialogues which produced them from those with which we are now engaged."2

Eu jamais havia lido o nome de Gayle Rubin. Foi numa disciplina de pós-graduação que me deparei com a publicação mexicana de "Tráfico de mulheres: notas para uma economia política do sexo", ${ }^{3}$ talvez seu artigo mais lido entre jovens pesquisadoras brasileiras que, como eu, investigam questões ligadas ao 'sistema sexo/gênero', como Rubin o chamou naquele momento. Tinha claro para mim, antes de lê-lo, que se tratava de um estudo de caso ou etnografia de escravas sexuais de países pobres em busca de trabalho na Europa. Não poderia estar mais enganada.

Em Deviations, a autora agrupa reflexões posteriores a seus textos mais importantes e conta, entre outras coisas, que se soubesse que a taxonomia do 'tráfico de mulheres' voltaria a ser utilizada como fora na primeira metade do século $X X$, em suas últimas décadas, nos EUA, teria escolhido outro título para seu ensaio.

Periodically a student will ask me about some article they think I have written about 'sex trafficking'. However, I had not written about sex trafficking, and certainly not in the sense in which that term is now often used. Specifically, I do not embrace the pervasive contemporary confusions between trafficking and prostitution, and in fact oppose them. (15\%)

No capítulo "The Trouble with Trafficking: Afterthoughts on the Traffick in Women", ela parte de um ensaio de Emma Goldman ${ }^{4}$ e mobiliza uma série de estudos produzidos nos Estados Unidos para desconstruir a associação automática entre o termo "tráfico" e a prostituição, criticando e mapeando os discursos e os interesses envolvidos na criação desse problema social.

Reflexões desse tipo tornam o livro um documento importante para a história intelectual em diversos recortes: estadunidense, do gênero, das lésbicas, do movimento feminista, das teorias queer. No volume Rubin retoma sua própria história para evidenciar o contexto de elaboração de cada estudo que gerou cada texto escolhido para a coletânea. Complementados por escritos mais recentes, os textos originais ganham nova luz e vivacidade. O livro é dividido em 14 capítulos que formam um panorama completo da obra da autora e de suas contribuições a diferentes campos de estudos.

É possível acompanhar as transformações na produção intelectual de Gayle Rubin ao longo do tempo e relacioná-las ao contexto político em que aconteceram. A produção da autora, que provocou reações odiosas dos grupos feministas antipornografia nos anos 1970 e 1980, acompanha e incita o desenvolvimento dos estudos de gênero, dos estudos sobre sexualidade, práticas e políticas sexuais e, mais recentemente, dos estudos queer. Embora mais propriamente discutida nos dois primeiros capítulos do livro, a ideia de "gênero" segue presente no trabalho da autora. O sólido capítulo "Of Catamites and Kings: Reflections on Butch, Gender and Boundaries", por exemplo, discute o gênero entre lésbicas como forma de forçar e testar os limites da interseção entre gênero e sexualidade.

Marcada pela militância feminista e lésbica de sua autora, a obra dá grande importância aos textos de posicionamento nas chamadas "feminist sex wars" e na política sexual estadunidense de forma geral. Nos capítulos "The Leather Menace: Comments on Politics and S/M", "Thinking Sex: Notes for a Radical Theory of the Politics of Sexuality", "Afterword to Thinking Sex", "Postscript to Thinking Sex", "Blood under the Bridge: Reflections on Thinking Sex" e "Misguided, Dangerous and Worng: An Analysis of Antipornography Politics", deparamo-nos com diferentes momentos e embates do movimento feminista estadunidense. Uma grande parte das feministas da 'segunda onda' teria se posicionado 
fortemente contra a pornografia e outras práticas sexuais que consideravam 'violentas' ou 'degradantes' para as mulheres, aliando-se a setores politicamente conservadores nessa luta. Não apenas enquanto militante feminista mas também como praticante do sadomasoquismo, uma das práticas demonizadas por esses grupos, Rubin critica essa tomada de posição.

[...] Instead of criticizing the sexist content of sexually explicit media and calling for the production of nonsexist, pro-feminist, or womanoriented sexual materials, feminists concerned with porn simply demanded that it be eliminated altogether.

[...] Important distinctions, such as those between sex and violence, image and act, harmless fantasy and criminal assault, the sexually explicit and the explicitly violent, were hopelessly blurred. $(52 \%)$

Durante as disputas em torno da pornografia, adotando sempre um posição muito crítica em relação a políticas sexuais, Rubin nota que esse tipo de política ataca principalmente os grupos cujas práticas sexuais são não-dominantes: homossexuais, sadomasoquistas, praticantes de swing, frequentadores de casas de fetiche, aqueles que se chamam de poliamoristas, entre outros. Essa inquietação abre com força o segundo eixo de concentração do livro: estudos sobre as comunidades gays e sobre as comunidades agregadas em torno de certas práticas sexuais entre essas 'renegadas'.

Tanto as políticas sexuais apoiadas pelas feministas antipornografia quanto as políticas de inibição ao suposto 'tráfico sexual' são mencionadas ao longo do livro, sobretudo no capítulo "The Leather Menace: Comments on Politics and S/M", como poderosos instrumentos legais para punir, perseguir e desmantelar tais comunidades. A partir dessa percepção a autora produz uma série de contribuições aos estudos sobre essas populações.

Há reflexões sobre o fluxo migratório e outras dinâmicas dessas pessoas em função de centros urbanos, por exemplo, no capítulo "Studying Sexual Subcultures: Excavating the Etnography of Gay Communities in Urban North America". A descrição etnográfica das festas sadomasoquistas no clube chamado The Catacombs é um dos pontos altos. O capítulo "The Catacombs: A Temple of the Butthole" intercala riquíssimos detalhes da dinâmica das festas e da construção do ambiente, planejado para tais festas, com dados importantes sobre o desenvolvimento da comunidade sadomasoquista em São Francisco.
'Out front' was distinguished from 'the back'. In the front room, people socialized, smoked, drank, flirted, negotiated and came up for air. [...] There was no smoking, eating or drinking permitted in the back rooms. The back was not for casual socializing. The back was for sex. [...] All the way in the back, was the dungeon. Just walking into that room could put a person in a leathery mood. The dungeon had big exposed wood beams and posts. It had a wood plank floor sanded smooth as baby skin and covered at all times with a thin sheen of Crisco. There were mirrors on the walls and ceilings. (47\%)

Já o texto "Geologies of Queer Studies: It's Déjà Vu all over again" traz um relato da história intelectual dos estudos anglófonos sobre sexualidade. A edição conta ainda com a rica introdução de Rubin para a edição estadunidense de 1976 da obra "A Woman Appeared to me", da escritora lésbica Renée Vivien, cuja biografia foi um dos primeiro objetos de estudo da antropóloga. Ambos os capítulos fazem parte da dedicação da autora, ao longo de sua vida, em preservar e refletir sobre a história intelectual e sobre as práticas políticas das diferentes comunidades gay.

Uma entrevista realizada com ela pela filósofa Judith Butler constitui o Capítulo 12 da publicação - "Sexual Traffic: Interview with Gayle Rubin by Judith Butler" - ${ }^{5}$ e funciona como uma costura dos campos de interesse intelectual de Rubin. A partir das questões de Butler, Gayle Rubin esclarece e explicita o arcabouço teórico e os diálogos que the permitiram produzir sua obra. Essencialmente, esse processo ainda é reforçado e instigado pelo engajamento político da antropóloga, que apresenta uma visão muito lúcida e reflexiva dos fatos concretos em que esteve imersa ao escrever grande parte dos textos. Como se produziram essas ideias, influentes hoje em muitos aspectos, é a questão que a entrevista assim como o livro todo são capazes de brilhantemente responder.

All of the essays collected here deal in some way with a set of concerns I have been engaged with during the last four decades: gender, sexuality, power, politics, institutions, and what Charles Tilly has called 'durable inequalities'. I have been concerned with how these things are located in specific times, places and cultural contexts, and in how knowledge of them is assembled, preserved, and transmitted (or not). [...] Preparing this collection has forced me to think about why they were written, the conditions that molded them, and the persistent themes with which they have wrestled. $(1 \%)$ 


\section{Notas}

1 "Kindle" é um modelo popular nos EUA de leitor de ebooks, livros eletrônicos. Permite a compra e o download de livros digitais. Uma vez que é possível mudar o tamanho da fonte de leitura e, portanto, a quantidade de texto em cada "página", a marcação das páginas é feita através da proporção do total do livro lida. Assim, as citações aqui presentes referem-se à proporção do texto. Ainda não há regra $A B N T$ para esse tipo de publicação em que a numeração das páginas é ausente.

${ }^{2}$ Gayle RUBIN, 2011 , $1 \%$.

${ }^{3}$ RUBIN, 1986.

${ }^{4}$ Emma GOLDMAN, 2002.

${ }^{5}$ Esta entrevista já foi publicada no Brasil com o título de "Tráfico sexual: entrevista" (RUBIN e Judith BUTLER, 2003).

\section{Referências}

GOLDMAN, Emma. "The Traffic in Women." Hastings Women's LJ, n. 13, p. 9, 2002.

RUBIN, Gayle. "El tráfico de mujeres: notas sobre la 'economia política' del sexo". Nueva Antropología, México, v. VIII, n. 30, p. 95145, 1986

RUBIN, Gayle; BUTLER, Judith. "Tráfico sexual: entrevista". Cadernos Pagu, Campinas, n. 21, 2003. Disponível em: <http://www.scielo.br/ scielo.php?script $=$ sci_arttext\&pid $=$ S0104 83332003000200008 \& $\mathrm{Ing}=$ en\& $\mathrm{nrm}=$ iso $>$. Acesso em: 15 abr. 2012.

Marília Barbara F. Garcia Moschkovich Universidade Estadual de Campinas 